\title{
SISTEM INFORMASI PENJUALAN ONLINE (E-COMMERCE) MENGGUNAKAN CMS WORDPRESS PADA TOKO SORAYA SHOP DENGAN MENERAPKAN METODE RAD
}

\author{
Dippos Manulang $^{1}$, Leon Andretti Abdillah ${ }^{2}$, Kurniawan ${ }^{3}$ \\ ${ }^{-3}$ Program Studi Sistem Informasi, Universitas Bina Darma \\ Jalan Ahmad Yani No. 3, Plaju, Palembang \\ 1ippospiramida@gmail.com, ${ }^{2 *}$ leon.abdillah@yahoo.com, ${ }^{3}$ kurniawan@ mail.biandarma.ac.id
}

\begin{abstract}
ABSTRCT
Current IT development offer many easyness in business. Soraya Shop is a business in selling women's clothing.one of the problem is But sales problems sometimes still be one of the obstacles to achieving corporate objectives, since the sales system is still done manually. To enchance that problem, authors develop an electronic commerce by using CMS wordpress. $e$, the deals are still done manually, dam management of data that has not been structured and lack of means of purchase and payment online or via account transfer. Then built a Sales Information System Online at Soraya Shop that will be using the programming language PHP. With this system is expected to help Soraya Shop in marketing online sales of women's clothing and fast it is used CMS WordPress. By applying the method of Rapid Application Development to expedite their preparation and the estimated time is shorter. And related to that issue of writing the thesis according to information obtained from Soraya Shop.
\end{abstract}

Keywords: e-Commerce, CMS, Wordpress.

\section{PENDAHULUAN}

Di era globalisasi seperti saat ini, perkembangan teknologi informasi (TI) yang sangat pesat telah memengaruhi interaksi antar individu, antar kelompok, dan antar negara. Kebutuhan akan TI menempati prioritas yang tinggi. Kebutuhan tersebut belum bisa didapat di berbagai media seperti koran, majalah, radio, televisi. Media informasi yang paling banyak diminati saat ini dapat diakses melalui internet. Banyak aplikasi di internet yang dibuat untuk mendukung berbagai kebutuhan seperti untuk pemerintahan, pendidikan, bahkan untuk dunia bisnis. Dalam dunia bisnis telah marak dengan munculnya suatu istilah electronic commerce (e-Commerce).

e-Commerce merupakan jual beli atau pertukaran produk, jasa dan informasi melalui jaringan informasi termasuk internet (Turban, Leidner, McLean, \& Wetherbe, 2008). Faktor-faktor yang menjadi pendorong implementasi e-commerce, menurut Desruelle dan Burgelman (2001) meliputi: 1) Globalisasi dan liberalisasi perdagangan, 2) Kompetisi yang semakin tajam, 3) Perkembangan teknologi, 4) Pengurangan tujuan secara fisik, dan 5) Publisitas. Dengan menggunakan e-Commerce konsumen bebas bertransaksi dan menentukan produk yang akan dibeli dari sejulah vendor (Rofiq, 2007).

Sebuah website e-Commerce dapat didesain dengan 2 (dua) metode yaitu 1) Hosted e-commerce platforms, atau 2) Content Management System (CMS). Pada penelitian ini penulis lebih menggunakan kemudahan-kemudahan yang ditawarkan oleh CMS. Dalam hal ini, konten yang dimaksud adalah produk pakaian yang akan menjadi isi dari website. Dan salah satu contoh penggunaan CMS pada -Commerce yaitu CMS WordPress. CMS WordPress adalah salah satu platform yang bisa digunakan untuk membangun sebuah online shop yang profesional, yang diperlukan untuk disiapkan adalah nama domain untuk website, hosting, dan juga template untuk online shop tersebut (Alfiah, Witjaksono, Rizwan, Hardianto, \& Darwanti, 2015). Wordpress merupakan platform untuk blog yang sangat populer dan mudah digunakan (Abdillah, 2013, 2014b).

Untuk mengembangkan web e-Commerce ini, penulis mengikui metode Rapid Application Development (RAD). RAD adalah sebuah strategi pengembangan sistem yang menekankan kecepatan dalam pengembangan melalui keterlibatan pengguna dalam pembangunan secara cepat, iteratif, dan incremental dari serangkaian prototype dari suatu sistem yang dapat berkembang menjadi suatu sistem akhir atau versi tertentu (Whitten \& Bentley, 2007).

Soraya Shop adalah toko yang menjual pakaian wanita dengan desain yang modern, dimana proses penjualannya yaitu pelanggan datang langsung ke toko dan memilih pakaian yang ingin dibeli sesuai dengan selera pelanggan. Dengan kemajuan teknologi sampai saat ini Soraya Shop belum mempunyai sebuah sistem penjualan online (e-Commerce). Namun masalah penjualan terkadang masih menjadi salah satu kendala untuk mencapai tujuan perusahaan, karena sistem penjualan yang masih dilakukan secara manual, transaksi yang masih dilakukan secara manual. Oleh karena itu, dalam kondisi persaingan penjualan yang cukup ketat, Toko Soraya Shop berkeinginan untuk mengembangkan atau menerapkan $e$-Commerce dengan menggunakan CMS Wordpress dan RAD. Dengan kebijakan ini, diharapkan dapat meningkatkan : 1) kepuasan pelanggan 
agar dapat bertahan, 2) penjualan, 3) luas pasaran, dan 4) hubungan dengan pelanggan yang memungkinkan terciptanya kesetian pelanggan bukan hanya pada produknya namun juga setia terhadap perusahaan.

\section{METODOLOGI PENELITIAN}

\section{A. Tempat Penelitian}

Lokasi penelitian ini dilaksanakan pada Toko Soraya Shop Palembang. Toko ini beralamat di Jalan Ahmad Yani, Plaju, Palembang. Waktu ang dibutuhkan utnuk melakukan penelitian ini sekitar 6 (enam) bulan. Penelitian ini dimulai pada bulan Oktober 2016 sampai dengan bulan Februari 2017.

\section{B. Metode Pengumpulan Data}

Adapun metode pengumpulan data yang digunakan dalam menyelesaikan penelitian ini, antara lain: 1) Wawancara (Interview), merupakan suatu pengumpulan data yang dilakukan dengan cara tanya jawab atau dialog secara langsung dengan pihak-pihak yang terkait dengan penelitian yang dilakukan. Dalam hal ini penulis melakukan tanya jawab kepada Manager Toko Soraya Shop, 2) Pengamatan (Observation), yaitu metode pengumpulan data dengan cara mengadakan tinjauan secara langsung ke objek yang diteliti. Untuk mendapatkan data yang bersifat nyata dan meyakinkan maka penulis melakukan pengamatan langsung pada Toko Soraya Shop, dan 3) Studi Pustaka. Untuk mendapatkan data-data yang bersifat teoritis maka penulis melakukan pengumpulan data dengan cara membaca dan mempelajari buku-buku, makalah atau pun referensi lain yang berhubungan dengan masalah yang dibahas.

\section{Rapid Application Development (RAD)}

Metode pengembangan yang digunakan untuk membangun e-Commerce berbasis CMS Wordpress ini adalah Rapid Application Development (RAD). Rapid application development (RAD) adalah pendekatan berorientasi objek untuk pengembangan sistem yang melibatkan suatu metode pengebangan sekaligus software tools (Kendall \& Kendall, 2011). Ada 3 (tiga) fase dalam RAD yang melibatkan penganalisis dan pengguna dalam tahap penilaian, perancangan, dan penerapan. Adapun ketiga fase tersebut adalah 1) Requirements Planning (perencanaan Kebutuhan), 2) RAD Design Workshop (desain kerja RAD), dan 3) Implementation (Implementasi).

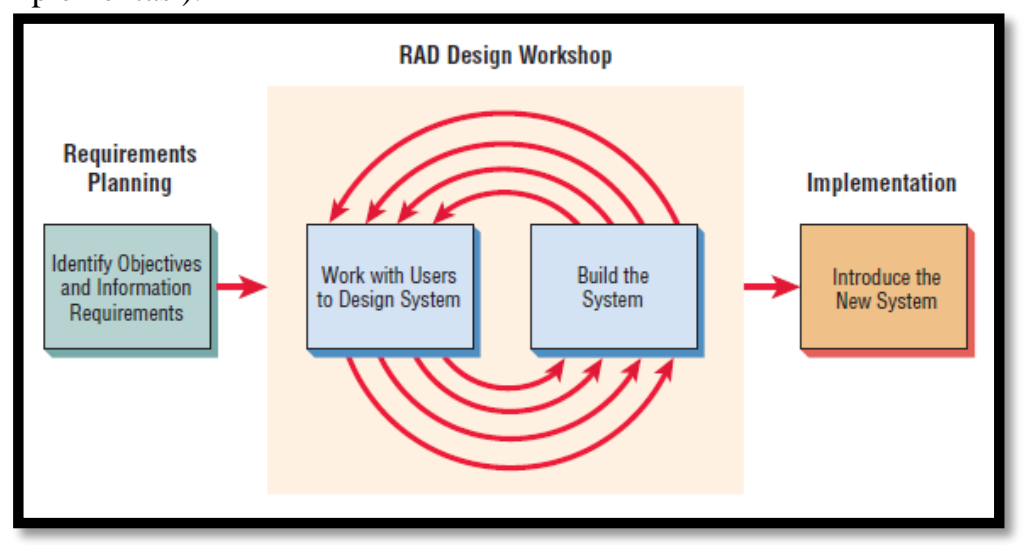

Gambar 1. Model RAD

Proses pembangunan web e-Commerce untuk memperkenalkan dan menjual produk unggulannya kepada masyarakat luas dengan menggunakan RAD hanya membutuhkan waktu sekitar 60 hari. Kebutuhan yang mendesak akan pembangunan web E-Commerce, menjadi alasan terpilihnya metode pengembangan RAD agar keinginan masyarakat dapat segera terpenuhi (Kosasi \& Yuliani, 2015).

\section{Implementasi CMS Wordpress}

Berikut adalah penjelasan dari tahap-tahap pengimplementasian CMS WordPress: 1) Membuat domain dan hosting. Pada pembuatan e-commerce ini diperlukan domain dan hosting sebagai identitas bisnis didunia internet, 2) Meng-install wordpress dan template. Pada tahapan ini wordpress dan template harus di-install agar lebih mudah dalam pembuatan dan pengaturan tampilan pada e-commerce ini tanpa harus online, 3) Meng-install plugin. 


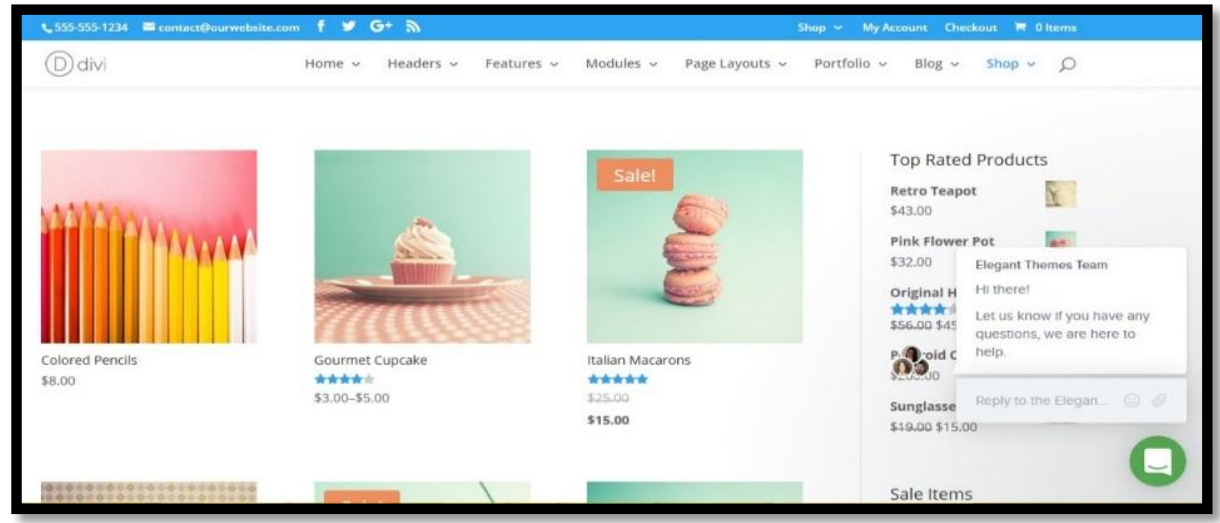

Gambar 2. CMS WordPress e-Commerce

Untuk mendukung performa e-Commerce ini diperlukan plugin agar terlihat lebih menarik dan menjadi efektif, 4) Mengatur toko online. Pada tahapan ini terdapat general settings, mengatur tampilan depan, mengatur administrasi, mengatur pengiriman, pilihan pembayaran, dan transaksi, dan 5) Implementasi. Pada tahapan ini terdapat membuat kategori produk, variasi produk, menambah produk, mencoba bertransaksi, dan memeriksa order dan menyetujui transaksi.

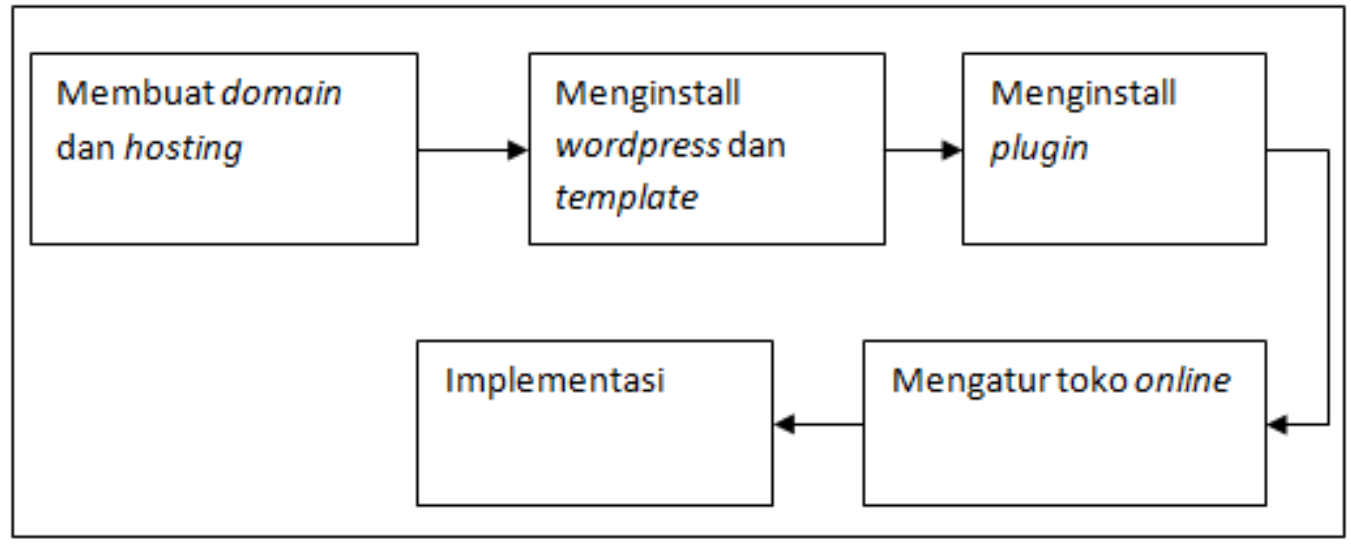

Gambar 3. Implementasi CMS WordPress

\section{HASIL DAN PEMBAHASAN}

Setelah semua tahapan yang ada selesai dikerjakan, maka didapatlah sebuah web e-Commerce berbasis CMS Wordpress. Sistem Informasi Penjualan Online ini menggunakan CMS WordPress serta menerapkan Metode RAD. Kelebihan utama dari skema ini adalah kecepatan dalam pengembangan sistemnya serta memanfaatkan template yang telah disediakan oleh CMS WordPress dan produk-produk yang dijual pada sistem ini akan terlihat lebih menarik ketika menggunakan template ini. Pada sistem ini juga mampu mengelola data barang atau produk yang dijual secara terstruktur.

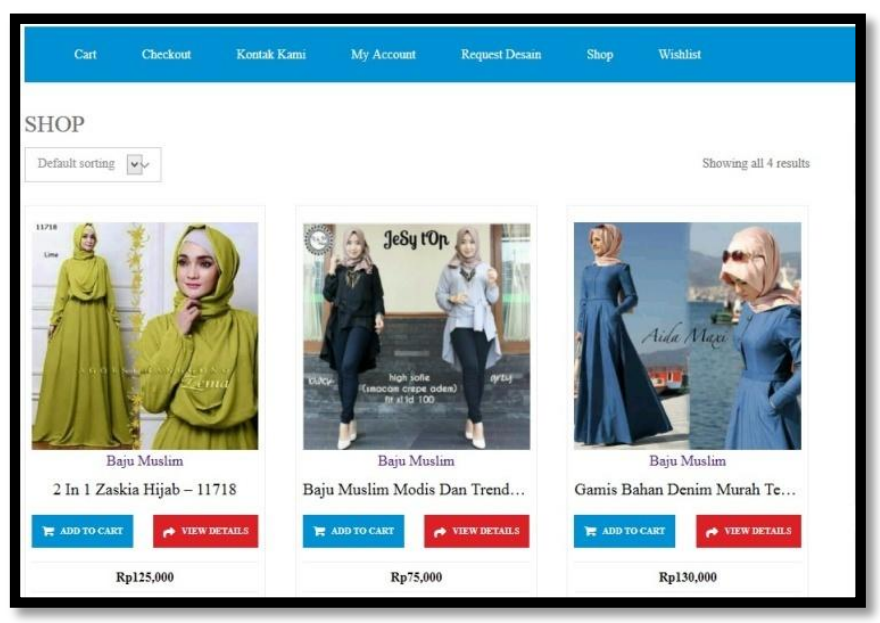

Gambar 4. Halaman Utama. 


\section{A. Menu Utama}

Menu Utama merupakan halaman ang menampilkan daftar gambar koleksi Toko Soraya Shop. Tampilan halaman utama dapat dilihat pada Gambar 4. Pada masing-masing gambar ada 2 (dua) tombol, yaitu : 1) Tombol "Add To Chart", dan 2) Tombol "View Details". Jika pembeli tertarik untuk membeli barang tersebut, maka dapat dengan menekan tombol "Add To Chart". Jika pembeli ingin melihat rincian dari produk tersebut, dapat menekan tombol "View Details".

\section{B. Menu Chart}

Menu "Chart" digunakan untuk melayani proses pembelian barang. Pada menu ini, akan menampilkan gambar produk yang diinginkan oleh pembeli. Jika pembeli memiliki "Coupon" untuk potongan harga, maka kodenya dapat dimasukkan pada isian "Coupon code" diikuti dengan menekan tombol "Apply Coupon". Untuk mengetahui "Total Price", pembeli dapat melihatnya setelah memasukkan "Quantity" dan menekan tombol "Update Chart". Untuk melakukan pembayaran, maka pembeli melakukan konfirmasi dengan menekan tombol "Proceed To CheckOut".

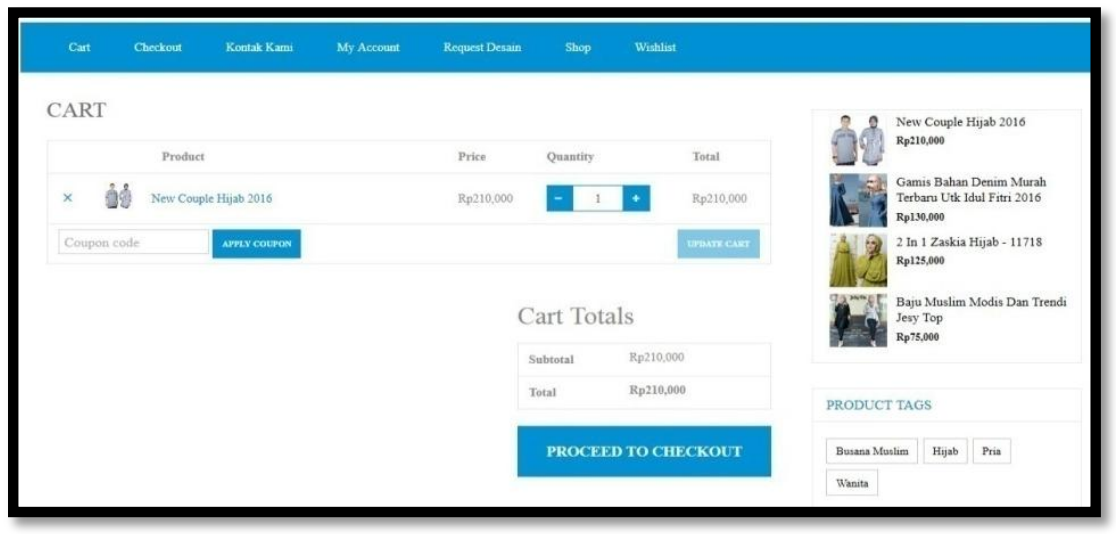

Gambar 5. Menu “Chart”.

\section{Menu "CheckOut Member"}

Menu "CheckOut" digunakan untuk melayani proses pembayaran barang. Pada menu ini, akan menampilkan gambar isian "Billing Details". Isian untuk "Billing Details" terdiri atas: 1) "First Name", 2) "Last Name", 3) "Company Name", 4) "Email Address", 5) "Phone", 6) "Country", 7) "Address", 8) "Town/City", dan 8) "Additional Information". Tampilan menu "CheckOut" dapat dilihat pada Gambar 6.

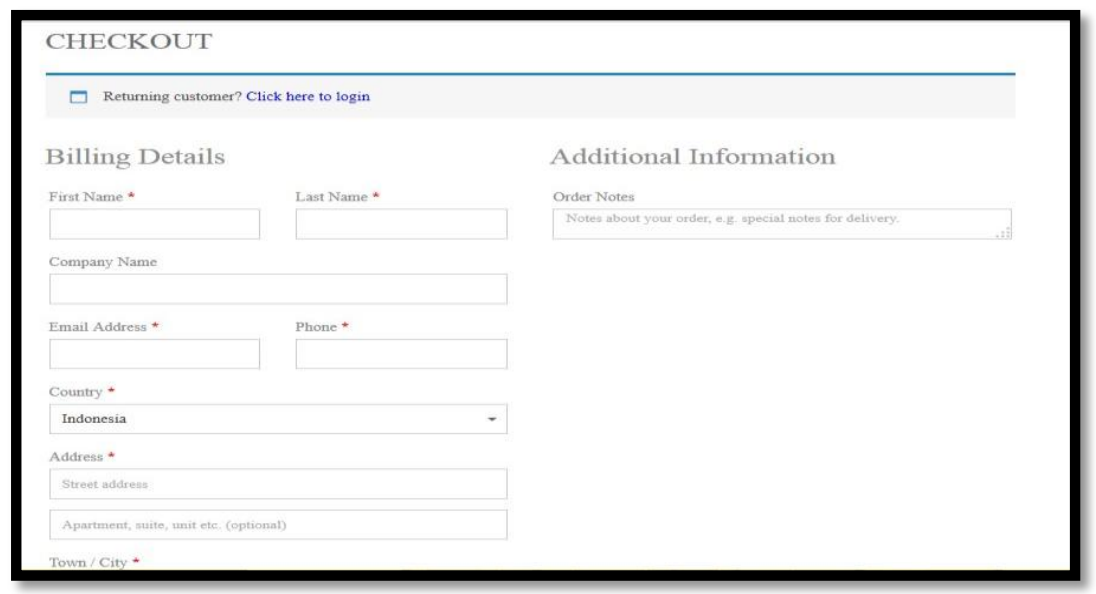

Gambar 6. Menu "CheckOut”.

\section{Menu "MyAccount"}

Menu "My Account" merupakan halaman bagi "Member" setelah melakukan pendaftaran. Menu ini memiliki 6 (enam) sub-menu, yaitu: 1) "Dashboard", 2) “Orders", 3) "Download", 4) “Address", 5) “Account Details", dan 6) "Logout". Tampilan menu "Dashboard Member" dapat dilihat pada Gambar 7. 


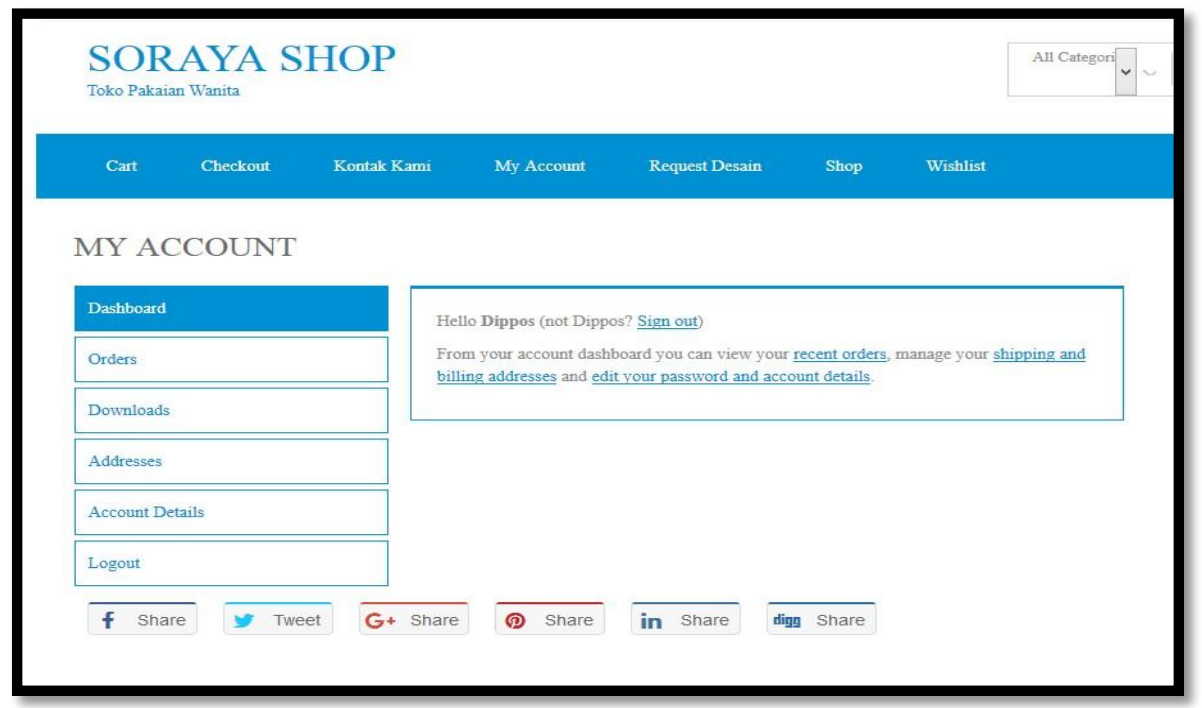

Gambar 7. Menu "My Account".

\section{SIMPULAN}

Berdasarkan uraian yang telah dikemukakan pada hasil dan pembahasan sebelumnya, maka dapat ditarik beberapa kesimpulan dalam mencapai tujuan yang diinginkan. Adapun kesimpulan yang dapat diambil adalah sebagai berikut:

1) Penelitian ini menghasilkan sebuah sistem informasi penjualan online yang menyediakan berbagai jenis pakaian wanita yang di jual pada Toko Soraya Shop.

2) Menyajikan tampilan penjualan online yang menarik dan mempermudah customer dalam melakukan pembelanjaan online di Toko Soraya Shop, dengan CMS WordPress.

3) Mempermudah admin dalam mengelolah data penjualan yang akan di-input-kan dalam sistem.

4) Berdasarkan kesimpulan di atas, maka ada beberapa saran yang penulis sampaikan antara lain: a) Perlu adanya pemeliharaan khusus untuk memelihara program sehingga dapat di lihat perlu adanya perbaiakn dan penyempurnaan kembali atau perlu di kembangkan lebih lanjut lagi, 2) Diperlukan pelatihan bagi pengguna sistem ini agar dapat lebih mudah dalam penggunanya.

5) Untuk penelitian selanjutnya, Sistem Informasi yang ada bisa dilengkapi dengan fitur untuk "sharing" ke "social media". Karena social media sangat bagus untuk "promotion and marketing" (Rahadi \& Abdillah, 2013). Apalagi Indonesia masuk ke dalam jajaran 5 (lima) besar pengguna "Facebook" di dunia (Abdillah, 2014a).

\section{DAFTAR PUSTAKA}

Abdillah, L. A. (2013). Students learning center strategy based on e-learning and blogs. Paper presented at the Seminar Nasional Sains dan Teknologi (SNST) ke-4 Tahun 2013, Fakultas Teknik Universitas Wahid Hasyim Semarang.

Abdillah, L. A. (2014a). Indonesian's presidential social media campaigns. Paper presented at the Seminar Nasional Sistem Informasi Indonesia (SESINDO2014), ITS, Surabaya.

Abdillah, L. A. (2014b). Managing information and knowledge sharing cultures in higher educations institutions. Paper presented at the The 11th International Research Conference on Quality, Innovation, and Knowledge Management (QIK2014), The Trans Luxury Hotel, Bandung, Indonesia.

Alfiah, F., Witjaksono, A., Rizwan, N., Hardianto, B., \& Darwanti, T. (2015, 6-8 Februari 2015). Penerapan Teknologi e-Commerce Menggunakan CMS Wordpress sebagai Platform pada Online Shop. Paper presented at the Seminar Nasional Teknologi Informasi dan Multimedia (Semnasteknomedia2015), Yogyakarta.

Desruelle, P., \& Burgelman, J.-C. (2001). The impact of e-commerce on the value chain. The Journal of Policy, Regulation and Strategy for Telecomunication, Information and Media, 3(6), 485-497.

Kendall, K. E., \& Kendall, J. E. (2011). Systems analysis and design (8th ed.). Upper Saddle River, New Jersey: Prentice-Hall.

Kosasi, S., \& Yuliani, I. D. A. E. (2015). Penerapan Rapid Application Developent pada Sistem Penjualan Sepeda Online. Simetris: Jurnal Teknik Mesin, Elektro dan Ilmu Komputer, 6(1), 27-36.

Rahadi, D. R., \& Abdillah, L. A. (2013). The utilization of social networking as promotion media (Case study: Handicraft business in Palembang). Paper presented at the Seminar Nasional Sistem Informasi Indonesia (SESINDO2013), Inna Grand Bali Beach Sanur \& STIKOM Bali, Bali. 
Rofiq, A. (2007). Pengaruh dimensi kepercayaan (trust) terhadap partisipasi pelanggan E-commerce. Magister Manajemen Tesis, Universitas Brawijaya, Malang.

Turban, E., Leidner, D., McLean, E., \& Wetherbe, J. (2008). Information Technology for Management. New York: John Wiley \& Sons.

Whitten, J. L., \& Bentley, L. (2007). Systems analysis and design methods (7th ed.): McGraw-Hill Professional. 